\title{
TEKNIK PROPAGANDA IDEOLOGI INTERNASIONALISME DALAM NOVEL RASA MERDIKA KARYA SOEMANTRI
}

\author{
Agus Sulton \\ Universitas Hasyim Asy'ari Tebuireng Jombang. \\ agus_sul@yahoo.com
}

\begin{abstract}
Abstrak
Penelitian ini akan membicarakan teknik propaganda yang terdapat dalam novel Rasa Merdika karya Soemantri. Teknik yang digunakan untuk analisis didasarkan teknik propaganda Combs Alfred McClung Lee, Elizabeth Briant Lee. Metode penelitian ini memanfaatkan metode deskriptif kualitatif, yakni mendeskripsikan sekaligus pembacaan ideologi internasionalisme yang disampaikan pengarang. Hasil temuan penelitian ini membuktikan, bahwa novel Rasa Merdika dianggap berbahaya dan mengancam keberadaan pemerintah dan para pemodal. Karya-karya atau bacaan yang dianggap bacaan liar ini memberikan propaganda dan bentuk protes kepada pemerintah.
\end{abstract}

Kata Kunci: Novel Rasa Merdika, ideologi internasionalisme, teknik propaganda, dan protes

\section{PENDAHULUAN}

Karya sastra yang lebih luas membahas mengenai kebudayaan sosial salah satunya adalah jenis novel. Dalam pandangan Shklovsky (Selden, 1985: 43), unsur kesusastraan yang paling esensial dilakukan oleh suatu novel. Novel ibarat teks cerminan dunia naratif yang mengundang banyak persepsi. Di dalamnya merekam peristiwa-peristiwa yang ada di masyarakat, termasuk situasi sosial dan politik saat karya itu diciptakan. Dalam hal ini, beberapa karya fiksi pada awal 1900-an secara tekstual mempersoalkan strategi komunikasi, propaganda, dan agitasi kepada pembaca (Sulton, 2015).

Berdasarkan Ruth T. McVey (1965: 1), komintern merupakan suatu organisasi komunis internasional yang bermarkas di Uni Soviet, berdiri pada tahun 1919. Organisasi ini punya kepentingan mengajarkan filsafat Marxisme-Leninisme di negara-negara berkembang di seluruh dunia, yaitu negara yang terjajah di kawasan Asia, Afrika, termasuk Amerika Selatan yang dikuasai oleh kekuatan kapitalis Eropa dan Amerika Serikat. 
Komintern selama membangun basis di Asia banyak terjadi kegagalan, sehingga Lenin menyarankan untuk komintern Asia harus bekerja sama dengan kaum terpejalar dalam bergerakan Nasional. Selanjutnya, pada tahun 1920 Partai Komunis Indonesia (PKI) baru bergabung dengan komintern. Suasana ini menambahkan kaum pergerakan bertambah kuat dan revolusioner. Pada tangga 21 Januari 1922 sampai tahun 1923 terjadi pemogokan besar-besaran di beberapa perusahaan pegadaian dan kereta api (Sulton, 2020).

\section{Novel Rasa Merdika karya} Soemantri merupakan karya yang muncul di era tahun 1924 yang secara simbolis menyadarkan para buruh (kaum kromo). Dalam permulaan kata, novel ini ditulis Soemantri di dalam penjara Semarang lantaran terdakwa melanggar artikel 161 bis dari strafwetbook. Namun tulisan ini sebelumnya sudah pernah dimuat bersambung surat kabar Sinar Hindia sebagai feuilleton. Permulaan novel ini dikarang lantaran waktu itu--Soemantri dipenjara tidak ada kegiatan, dengan alas papan dan penerangan sinar matahari yang minim karena kurangnya jendela. Dari penjara itu, Soemantri dapat mengarang dua novel, yaitu Rasa Merdika dan Rahasia Terboeka.
Novel Rasa Merdika terbagi atas empat bagian, setiap bagian terbagi menjadi empat judul; (1) Dasar Merdika, (2) Pergi Mengoembara, (3) Debat, dan (4) Tergoda. Nuansa idealis dan syarat akan propaganda menjadi teks utama yang diangkat. Propaganda ideologi internasionalisme disampaikan melalui pengembangan antartokoh disertai bentukbentuk penyebab kemiskinan rakyat Hindia Belanda.

Dalam narasi teks novel Rasa Merdika dijelaskan bahwa rakyat Hindia Belanda yang tidak menyadari pada kondisi kemiskinan, beranggapan sebagai suatu takdir dari Tuhan. Orang-orang desa berbondong-bondog pergi ke kota untuk menjadi buruh (kuli). Sawah yang biasanya digarap oleh rakyat dipaksa untuk disewakan kepada pabrik-pabrik gula sebesar f.66,-. Karena itulah novel ini muncul saat kondisi sosial yang sama dengan penderitaan yang dialami masyarakat waktu itu. Soedarmo, tokoh propagandis dalam novel Rasa Merdika juga menyarankan untuk membaca suratsurat kabar yang memihak kepada kaum rakyat.

Gambaran kondisi sosial, ekonomi, dan politik di atas setidaknya menjadi bahan kajian yang menarik. Karena Rasa Merdika sebagai novel semangat kebebasan yang ingin keluar dari kolonialisme. Di dalam teksnya memuat 
syarat akan propaganda politik pergerakan.

Razif (2005) mengatakan, kalau bacaan seperti ini ditunjukan untuk kaum kromo, berbicara tentang banyak hal dengan katakata sihir seperti kapitalisme, vergadering, imperialisme, dan internasionalisme.

Propaganda dilancarkan dengan macam-macam cara. Menurut Dewi Yuliati, bahwa kesenian merupakan media propaganda yang tepat untuk mencari perhatian kepada masyarakat. Bentuk nyanyian sebagai salah satu bidang kesenian yang menjadi media propaganda yang tepat, karena lebih mudah disampaikan, dapat dinyanyikan secara bersama-sama, bisa membangkitkan emosi, dan memiliki efek menghibur. Nyanyian internationale adalah suatu nyanyian yang menjadi medium propaganda kelompok komintern. Nyanyian ini pada awalnya diciptakan untuk memperingati hari terbentuknya asosiasi buruh internasional pada tanggal 1 Mei 1864. Nyanyian internationale awalnya ditulis menggunakan bahasa Jerman, kemudian diterjemahkan ke dalam bahasa Belanda, Prancis, Inggris, Spanyol, Italia, Portugis, Denmark, Norwegia, Swedia, Rusia, Turki, dan Melayu. Penerjemahan syair legu tersebut dalam bahasa Melayu adalah Soewardi Suryaningrat.

Bangoenlah bangsa jang terhina!
Bangoenlah kamoe jang lapar!

Kehendak jang moelia dalem doenia

Senantiasa tambah besar

Lenjaplah adat pikiran toea!

Hamba rajat sadar, sadar!

Doenia telah berganti roepa

Nafsoelah soedah tersebar!

Kawan, kawan, hai ingatlah!

Ajo madjoe berperang!

Serikat internationale, jalah pertalian orang!

Negri ditindas, hoekoem berdusta

Jang kaja teroes hidoep seneng

Orang miskin terisap darahnja

Tak sekali berhak orang

Djangan soeka lagi terperintah!

Ingat aken persamaan

Wadjib dan hak tiada berpisah

Hak dan wadjib haroes sepadan

Kawan, kawan, hai ingatlah!

Ajo madjoe berperang!

Serikat internationale, jalan pertalian orang.

Dewi Yuliati kembali menambahkan, lagu internationale ini biasanya dinyanyikan pada saat berlangsung rapat-rapat organisasi buruh. Lagu ini menjadi lagu wajib yang harus 
dinyanyikan oleh siswa-siswa sekolah Sarekat Islam, ketika mereka bertugas mencari sumbangan untuk biaya operasional sekolah tersebut. Lagu ini diyakini kelompoknya dapat membangkitkan semangat anti kapitalisme dan imperialisme ini sangat diwaspadai oleh pemerintah kolonial, karena disebarluaskan melalui media surat kabar dan rapat-rapat umum. Penasihat urusan Bumiputera, R.A Kern (No. 501 x tentang kongres PKI ke-9 di Batavia, 7-10 Juni 1924), menyarankan kepada pemerintah kolonial supaya lebih berhati-hati, karena lagu itu menjadi nyanyian wajib untuk membuka dan menutup setiap vergadering (rapat).

Novel Rasa Merdika salah satu yang dicap bacaan liar pada waktu itu, ada kamungkinan novel ini sebagai media pembelajaran kepada pembaca atau sebatas menyadarkan kepada masyarakat untuk lepas dari kolonial Belanda, dan kehidupan peran serta tokoh-tokoh sebatas alat menyampaikan tujuan. Berdasarkan penilaian Pramoedya (2003, hlm. 119120), bahwa sastra pada awal abad ke-20 sudah mengawali dengan tradisi memenagkan objektivitas. Hal ini dapat dibuktikan dari isu-isu yang diangkat beberapa bertemakan realitas sosial dan aspirasi nasionalisme tanah Hindia dalam mengharapkan kemerdekaan.
Hal-hal inilah yang mendasari, mengapa novel ini perlu untuk diteliti dan diangkat ke permukaan lagi, terutama karya-karya yang dianggapnya "bacaan liar” oleh Rinkes (direktur Balai Pustaka). Setidaknya menemukan gambaran awal aktivitas kaum pergerakan yang berhaluan komunisme atau internasionalisme proletariat untuk merealisasikan ideologiideologi yang dianut agar segera lepas dari kolonialisme, imperialisme, dan feodalisme Belanda menjadi negara merdeka. Di pihak lain, pengkajian terhadap sastra-sastra di luar Balai Pustaka sekiranya menawarkan solusi untuk membukakan sejarah sastra Indonesia yang selama ini tonggak awalnya dimulai dengan produk-produk Balai Pustaka.

Berdasarkan alasan-alasan di atas, penelitian ini secara khusus melihat dari sudut pandang teknik propaganda ideologi internasionalisme. Pesan propaganda yang disampaikan di dalamnya tidak lepas dari kondisi dan situasi masa tahun 1920-an, bahwa sastra Indonesia masa awal sarat akan kritik dan pembelajaran kepada rakyat Hindia Belanda.

\section{LANDASAN TEORI}

Definisi propaganda mempunyai pengertian yang cukup luas. Menurut James E. Combs dan Dan Dimmo (1994: 23) menyimpulkan, bahwa propaganda 
adalah, (1) usaha yang disengaja atau sistematis untuk mencapai respon yang lebih jauh merupakan tujuan yang diinginkan oleh ahli propaganda, (2) sebuah usaha untuk mempengaruhi opini atau tingkah laku, (3) semua usaha yang mengagitasi orang-orang dalam suatu kepercayaan untuk suatu bentuk tindakan, (4) usaha untuk memberi pengaruh masyarakat dan mengontrol tingkah laku individual menuju pada tujuan akhir yang dinilai tidak ilmiah ataupun nilainya meragukan dalam masyarakat pada waktu yang ditentukan.

Menurut Lasswall (1972: 22), pada dasarnya propaganda bagian dari kontrol opini yang dilakukan dengan cara menyajikan simbol-simbol yang mempunyai arti atau menyampaikan argumen yang akurat melalui gambargambar, cerita, rumor dan informasi lain yang bisa digunakan dalam komunikasi sosial. Lebih lanjut, seorang pakar opini publik, Leonard W. Dobb (1950: 156) menyatakan, bahwa propaganda bisa dilakukan oleh komunikator kepada satu orang komunikan, tidak harus sebagai suatu kelompok terorganisir atau kepada masa lebih luas yang bersifat melembaga.

\section{Beberapa pengertian tersebut} menjadikan landasan titik temu pengertian peran penting propaganda-tidak lepas dari sebuah elemen pendukung seperti; (a) adanya komunikator sebagai lembaga komunikasi, (b) adanya komunikan atau penerima informasi, (c) politik propaganda yang menentukan isi dan tujuan yang hendak dicapai, (d) adanya pesan tertentu yang dirumuskan sedemikian rupa untuk mencapai tujuan efektif, (e) sarana, (f) adanya teknik yang selektif, dan (g) kondisi dan situasi yang memungkinkan dilakukan propaganda yang bersangkutan (Sastropoetro, 1991: 34-35).

Dalam konteksnya, elemen tersebut setidaknya sebagai pijakan mendukung keberadaan teori propaganda Walter Lippmann tahun 1922, dalam bukunya Public Opinion bahwa proses rangkain propaganda lahir dan berkembang dari kaum proletar (buruh tani, nelayan, dan dari kelas kurang berpendidikan) maupun pada golongan masyarakat paling bawah yang lain, hingga pengaruhnya berkembang naik mencapai pada golongan tertinggi, seperti kaum borjuis, kaum elit maupun golongan masyarakat tertinggi lainnya.

Rangkaian peristiwa teori propaganda Walter Lippmann dalam novel Rasa Merdika nampak dalam komunikasi yang dilakukan Soedjanmo kepada Tuan Vlammenhart. Soedjanmo memberikan pengaruh gagasan sebab-sebab kemiskinan di wilayahnya dan tradisi adat sembah kepada atasan. Padahal status Soedjanmo 
adalah orang bekerja magang rendahan di kantor Tuan Vlammenhart, controleur. Hal yang sama juga terlihat saat vergadering yang dilakukan Soedarmo. Acara itu telah berkumpul berbagai lapisan masyarakat rendahan sampai golongan status sosial tertinggi untuk mendengarkan propaganda komunisme dan internasionalisme dari Soedarmo.

Pada dasarnya propaganda adalah bentuk komunikasi permainan kata-kata yang mempunyai maksud tertentu. Hal ini, untuk melangsungkan serangkaian komunikasi tersebut diperlukan yang namanya teknik propaganda. Dalam Shoelhi (2012: 58-70) menjelaskan pendapat beberapa pakar mengenai teknik propaganda. Combs dan Dan Dimmo, Alfred McClung Lee, Elizabeth Briant Lee, dan Institute of Propaganda Analysis membagi teknik propaganda ke dalam sembilan bagian, yakni:

\section{Name calling (penjulukan)}

Propaganda jenis ini memberikan label buruk pada seseorang dan lembaga dengan menekankan gagasan simbol emosional. Target propaganda ini bertujuan untuk menolak dan mencaci pada seorang ataupun lembaga yang dituju tanpa harus mempertimbangkan fakta dan memeriksa atau mencari bukti pendukung kebenaran.
2. Glittering Generality (kemilau generalitas)

Teknik ini menghubungkan suatu dengan kata yang sangat baik untuk membuat target propaganda merasa senang sehingga bersedia menerima dan menyetujui ide yang ditawarkan secara mentah-mentah. Selain itu, teknik ini digunakan untuk membuat suatu ide, misi, atau visi diasosiasikan dengan hal-hal baik yang disukai kebanyakan orang, seperti keharuman, kekuatan, kelebihan, kebebasan, keadilan, dan demokrasi.

\section{Transfer (pengalihan)}

Pengalihan merupakan bentuk visualisasi konsep untuk mengalihkan karakter pada satu pihak tertentu. Teknik ini membawa otoritas, dukungan gengsi, dari suatu yang dihargai dan disanjung kepada suatu yang lain agar lebih dapat diterima.

4. Testimony (kesaksian)

Kesaksian digunakan untuk meminta dukungan seseorang yang berstatus sosial lebih tinggi untuk mengesahkan dan memperkuat argumennya dengan kesaksian orang tersebut.

5. Plain Folk (rakyat biasa)

Plain folk adalah suatu teknik propaganda yang menggunakan pendekatan yang implisit. Pada umumnya propaganda jenis ini sang 
propagandis menaruh sikap rendah hati dan empati dengan para korbannya.

6. Card Stacking (menimbangnimbang kartu untuk digunakan)

Teknik ini lebih pada memanfaatkan fakta atau kebohongan, ilustrasi atau penyimpangan, serta pernyataan logis atau tidak logis untuk memberikan kasus terbaik atau terburuk pada suatu gagasan, program, orang atau produk.

\section{Frustration or Scapegoat}

(menutupi frustrasi atau kambing hitam)

Teknik propaganda ini sang propagandis selalu menciptakan rasa kebencian ataupun menyalurkan frustrasinya untuk menciptakan kambing hitam pada lawannya.

8. Bandwagon (seruan mengikuti pihak mayoritas)

Teknik ini berisi imbauan kepada khalayak untuk ikut bergabung ke dalam kelompoknya karena dikelompoknya memiliki tujuan yang baik dan menyenagkan.

9. Fear Arousing (membangkitkan ketakutan)

Teknik fear arousing bertujuan untuk memperoleh dukungan dari target masa dengan menimbulkan sikap emosi negatif, khususnya ketakutan.

\section{METODE PENELITIAN}

Metode penelitian dalam memperlakukan novel Rasa Merdika ini memanfaatkan pendekatan deskriptif kualitatif melalui studi pustaka. Deskriptif kualitatif berarti suatu penelitian yang lebih menekankan analisisnya terhadap dinamika hubungan antar fenomena yang diamati, dengan menggunakan logika ilmiah (Azwar, 2005: 5). Fenomena penting mengenai propaganda ideologi internasionalisme yang terdapat dalam novel Rasa Merdika diperlakukan dari sudut pandang teknik propaganda internasionalisme sekaligus mengkomparasikan dengan kondisi dan situasi saat karya itu diproduksi. Dari situlah, muatan ideologi internasionalisme yang disampaikan pengarang dapat dimaknai sebagai wadah membukakan wawasan baru bagi pembacanya.

Bacaan novel yang dihasilkan oleh para tokoh pergerakan tahun 1923 dimanfaatkan untuk menyebarluaskan dan pemperkenalkan ideologi internasionalisme kepada rakyat Hindia Belanda. Pandangan ideologi internasionalisme dirasa sebagai alternatif yang relevan untuk menanggulangi kapitalisme, imperialisme, dan kolonialisme pemerintah Hindia. Upaya tersebut merupakan bagian semangat para organisatoris untuk melenyapkan kolonial 
Belanda dari bumi Hindia. Oleh sebab itu, narasi-narasi novel Rasa Merdika bagian dari usaha untuk memperkenalnya pengetahuan modern yang saat ini mulai berkembang.

\section{HASIL DAN PEMBAHASAN}

Teknik propaganda yang digunakan dalam organisasi pergerakan pada saat itu sebagai siasat pendidikan kepada masyarakat. Para tokoh pergerakan memanfaatkan media sastra untuk memainkan totoh-tokohnya yang idealis diharapkan pesan teks mampu diterima pembaca dengan baik dan terbentuk kesadaran pribadi. Dengan demikian, novel Rasa Merdika sebagai simbol relasi semangat zamannya akan dilakukan pendekatan dari aspek teknik propaganda politik tokoh-tokohnya. Teknik propaganda dalan novel Rasa Merdika terbagi menjadi beberapa bagian di bawah ini:

\section{Teknik Name Calling}

Propaganda name calling memberikan cap buruk atau stereotip kepada seseorang dan lembaga dengan sikap emosional. Propaganda model ini bersifat lebih menjatuhkan lawan atas suatu konsep, ideologi, dan kesewenang-wenangan. Propaganda jenis ini semacam tandingan ide, beranggapan ide atau lembaganya lebih baik dan benar dari pada lembaga lainnya.

Label buruk itu terlihat pada saat Soedjanmo melancarkan propaganda kepada Tuan Vlammenhart.

"Saja tidak perloe memboektikan toean. Kalau toean soeka pergi ke Solo dan Djokja toean bisa boektiken dari hal pengeranpengeran jang hilang harganja, disebabken karena roesak penghidoepannja, padahal mereka dahoeloe membesarken akan nafsoe kehormatannja....." (Soemantri, 1924: 28).

Sodjanmo secara emosional menjatuhkan keberadaan pangeranpangeran istana Solo dan Yogyakarta yang hilang harga dirinya lantaran kehidupannya sudah rusak. Argumentasi Soedjanmo itu untuk meyakinkan Tuan Vlammenhart tentang sebabsebab dari kemiskinan akibat dari pembagian hasil yang tidak merata, sendainya pembagian hasil sesuai prosedur sama rata sama rasa maka tidak akan terjadi kemiskinan dan nafsu kehormatan sembah kepada atasan akan hilang dengan sendirinya.

\section{Teknik Glittering Generality}

Propaganda glittering generality berupaya memberikan kata-kata yang bermakna sangat baik, gairah, atau 
mengandung spirit sehingga membuat target mau menerima dengan senang. Dalam novel Rasa Merdika bisa terlihat dalam propaganda Soedjanmo kepada Vlammenhart. Interaksi Soedjanmo ada yang perlu ditekankan untuk membangkitkan emosional Vlammenhart, yaitu kata

"minta dihormati" Napsoe "minta dihormati" itoe tidak aken bisa kekal padanja, kalau penghidoepannja roesak (Soemantri, 1924: 28).

Kata seperti itu menjadikan Vlammenhart berfikir, menajamkan pengertiannya. Dia tidak bisa membantah perkataan Soedjanmo, bahkan merasa malu. Perkataan yang sebelumnya kasar sekarang berbalik menjadi lemah lembut. Dalam kasus lain, ada kata "sama rata", kata tersebut ditujukan kepada Vlammenhart untuk menyatakan pembagian hasil yang merata agar nafsu kehormatan bisa hilang dan kemiskinan akan lenyap. Kemudian kata "hak diri" yang diungkapkan Sastro bermakna hak pribadi atau kapitalis.

Kata propaganda lainnya yang dapat menyihir komunikan adalah internasionalisme. Istilah tersebuh masih baru di kalangan masyarakat, baik masyarakat konteks novel maupun relitas masyarakat Hindia
Belanda. Ideologi internasionalisme diperkenalkan dalam vergadering sebagai langkah untuk melihat kemiskinan. Soedarmo juga menjelaskan internasionalisme mengobarkan perjuangan kelas buruh untuk menentang kapitalisme dengan harapan menjadikan kasta manusia.

\section{Teknik Transfer}

Transfer atau pengalihan berarti mengalihkan karakter pada suatu pihak, menyangkut kredibilitas sang propagandis. Propaganda pengalihan sifatnya eksternal prestise sang propagandis (track record), tidak ada keterkaitan dengan tema yang hendak disampaikan namun teknik pengalihan diharapkan bisa mempertegas ide propaganda.

Propaganda Soedjanmo, Sastro, dan Soedarmo yang track record terbaca (diketahui) para target propaganda hanya Sastro dan Soedarmo. Sastro menjadi abonnee dari sebuah surat kabar kaum buruh.

$$
\begin{aligned}
& \text {......lantaran Sastro adalah } \\
& \text { mendjadi abonnee dari } \\
& \text { seboeah soerat kabar kaoem } \\
& \text { boeroeh jang dengen berani } \\
& \text { membitjaraken segala } \\
& \text { apajang penting bagi kaoem } \\
& \text { kaoem boeroeh (Soemantri, } \\
& \text { 1924: 62). } \\
& \text { Dalam pandangan komunikan, }
\end{aligned}
$$
bekerja menjadi di surat kabar buruh 
dinilai orang yang pandai dan berpengetahuan luas. Berani dengan keras menyuarakan hak-hak dan pendapat kaum buruh, seperti halnya Soedarmo, seorang jurnalis dari kota S.

"Siapa jang aken bitjara?"

"Seorang djoernalist dari kota S."

(Soemantri, 1924: 63).

\section{Teknik Testimony}

Testimony adalah kesaksian pernyataan dari mereka yang memiliki kekuasaan pada gagasan-gagasan akurat. Propaganda kesaksian biasanya menggunakan seorang tokoh yang terkenal dan berpengaruh; pejabat negara, tokoh intelektual, atau tokoh lain yang relevan dengan propaganda yang disampaikan untuk meyakinkan target propaganda agar mempercayainya.

Penerapan teknik kesaksian berupa pengutipan sumber otoritas untuk membangun argumentasi. Teknik kesaksian hanya digunakan oleh Sastro untuk mempertegas pernyataannya kepada Nji Endang. Kesaksian itu bukan dari tokoh terkenal atau seorang pejabat, tetapi dari sebuah buku "Riwajat Pergaoelan Manoesia" yang tidak disebutkan pengarangnya.

"Ooh.....Dinda barangkali soedah pernah membatja tentang riwajat pergaoelan manoesia moelai dahoeloe kala, boekan?"

"Ja."

"Dalem riwajat pergaoelan manoesia boekankah soedah diseboetken bahasa kedjadian matjem sekarang itoe tidak ada" (Soemantri, 1924: 66).

Buku termasuk buah karya seorang intelektual menjadi landasan kesaksian Sastro. Setidaknya mampu merepresentasikan korelasi antara tema propaganda dengan teks dalam buku tersebut.

\section{Teknik Plain Folk}

Plain folk berarti rakyat biasa, maksudnya sang propagandis mempu bersatu akrab dengan target propaganda, sekaligus menunjukkan sikap dan kerendahan hati yang baik. Propaganda jenis ini merupakan strategi sang propagandis untuk berempati kepada komunikan, dan pada akhirnya komunikan yang menilai sikap sang propagandis.

Model propaganda plain folk dalam novel Rasa Merdika tampak pada tokoh Sastro dan Soedarmo. Sosok Sastro berbudi pekerti yang baik, penolong. Pada saat Sodjanmo baru diterima di firma Tuan Chef, Sastro lah yang mempersilahkan untuk tinggal di rumahnya. Kedekatan itu yang sampai terbawa arus propaganda Sastro, memperkenalkan ideologi 
internasionalisme. Soedjanmo menilai, sastro adalah orang yang berpendidikan dan mudah bergaul dengan siapapun, peramah dan pandai menjalin komunikasi. Tuan Chef adalah tokoh pembantu dalam novel Rasa Mardika. Chef ini seorang pemuda yang keluar dari sekolah dagang di Belanda, atas perintah direksinya di Eropa Tuan Chef ditugaskan memegang firma di kota P.

Propaganda Soedarmo dengan pendekatan plain folk, bisa dilihat pada saat vergadering dimulai, Soedarmo mulai berdiri dengan roman muka yang sedikit tersenyum. Memberikan tanda bahwa Soedarmo adalah sosok yang tegas. Seusai acara vergadering, Soedarmo berbicara akrab antara Sastro, Nji Endang, dan Soedjanmo. Ketiganya menanyakan soal vergadering yang baru berlangsung. Percakapan ketiganya sambil berjalan, sesampai dipertigaan mereka berpisah. Soedarmo hendak menginap di teman yang sudah lama dikenalnya di gerakan serikat buruh.

\section{Teknik Card Stacking}

Teknik propaganda card stacking merupakan pemilihan bukti atau fakta penguat dari teks inti propaganda. Dalam novel Rasa Merdika tokoh propagandis selalu menggunakan teknik ini. Teknik ini digunakan untuk membuat target propaganda bisa meyakini terhadap pesan sang propagandis.

Hal ini bisa dibuktikan pada saat Soedjanmo berbicara dengan Vlammenhart. Soedjanmo menjelaskan bahwa kemiskinan dan kekayaan timbulnya dari pembagian hasil yang tidak merata. Seumpama pembagian hasil bisa dibuat sama rata maka tidak akan terjadi kemiskinan dan nafsu ingin dihormati akan hilang dengan sendirinya. Dari pendapat Soedjanmo itu, Vlammenhart ingin mengetahui buktinya. Kemudian Soedjanmo menunjukkan buktinya, tapi bukti tersebut berupa pembicaraan implisit yang bermaksud Vlammenhart mau untuk mengamatinya. Vlammenhart ditunjukkan kota Solo dan Yogyakarta, di mana kedua kota itu pangeranpangerannya sama rusak harganya akibat rusak penghidupannya.

Upaya menarik perhatian tidak hanya dilakukan kepada Vlammenhart, tetapi Soedjanmo juga memakai teknik card stacking kepada Kromotjiloko. Soedjanmo sedikit tersinggung dipanggil Kromotjiloko "den", karena dasar kata "den" (raden) menurut Soedjanmo berasal dari kata "rah" dan "hadi" artinya darah yang baik budi dan wataknya. Kromotjiloko memanggil "den" berdasarkan 
kebiasaan yang berlaku di desanya, karena anak seorang pegawai-pagawai onderdistrict harus dipanggil "den" kalau tidak dipanggil "den" akan kena amarah. Ketika itu juga Soedjanmo menarik contoh realitas, bahwa panggilan "den" di sini (latar novel, Hindia Belanda) adalah anggapananggapan yang dirinya mengaku bangsawan dan raja-raja, dianggap bisa memimpin rakyatnya. Padahal para pemimpin itu membikin sengsara rakyat dan kehidupannya bersenangsenang dengan dayang-dayangnya. Namun, dahulu kala orang yang mendapat sebutan "den" atau raden benar-benar menjadi penolong masyarakat umum dan rajin membela kepentingan banyak orang, inilah yang pastas dipanggil "raden bagus".

Penerapan teknik card stacking digunakan juga oleh Soedarmo pada saat menjelaskan kapitalisme. Soedarmo menjelaskan pengertian bahwa dengan datangnya pabrik gula akan memberikan kesengsaraan pada masyarakat. Soedarmo membuktikan, bahwa dahulu orang di desa-desa hidup tentram dan berkecukupan, setelah datangnya kapitalisme orang menjadi "merdeka" maksudnya merdeka tanpa terpalut barang-barang yang dimiliki.

$\begin{array}{lll}\begin{array}{l}\text { Orang-orang } \\ \text { doeloenja }\end{array} & \begin{array}{c}\text { desa } \\ \text { masih }\end{array} & \text { jang } \\ \text { bisa }\end{array}$

mempoenjai barang sebidang doea bidang sawah laloe kehilangan miliknja itoe dan mereka laloe djatoeh dibawah pemerintahnja sekeroep-sekeroep dalem paberik, lantaran mereka soedah djadi merdeka, ertinja "merdeka" tidak terpaloet oleh barang sesoeatoe miliknja, hingga bisa diperintah oleh madjikannja dengen sesoeka-soeka (Soemantri, 1924: 78).

Soedarmo kembali menjelaskan, bahwa orang-orang penduduk desa menanami pohon bambu di pinggiran desanya dengan maksud agar orang lain yang punya niat jahat tidak bisa masuk ke rumah-rumah penduduk. Anggapan ini dinilai sangat salah oleh Soedarmo, kaum pemodal tetap bisa memaksa lahan-lahan garapan mereka. Fakta itu ditarik Soedarmo terhadap kasus yang terjadi di Cina untuk meyakinkan masa. Menurutnya, di sepanjang batas negeri Tiongkok berdiri pagar-pagar yang tebal, mekipun seperti itu kekuasaan imperialisme tetap bisa menerobos batas tembok-tembok yang tinggi, rakyat semakin lama mengalami kemiskinan.

Disepandjang batas negeri Tiongkok didiriken pagar jang terlaloe tebal dan tegoeh selang berabad-abad lamanja. Tetapi meskipoen begitoe, kekoeasaan dari imperialisme 
bisa menerobos pagar jang tebal dan tinggi itoe, jang ackhirnja sebagai api dalem kapoek, dari sedikit-kesedikit menanem kemelaratan pada Ra'jat dalem itoe negeri, dan disitoe djoega roesaklah kebangsaannja (Soemantri, 1924: 79).

Tanaman bambu adalah bukti nyata penduduk desa masa lampau. Pada waktu itu masyarakat di desa masih mencintai tanah tumpah darahnya. Tidak ada penduduk desa yang pergi ke kota lantaran jadi kuli. Namun setelah kapitalis datang ke penduduk desa, mereka berbondong-bondong mencari penghidupan ke kota.

"Kalau kita pelesir sebentar didesa-desa disitoe kita masih bisa melihat bekasbekasnja orang jang dapet mentjintai tanah toempah darahnja" (Soemantri, 1924: 79).

\section{Teknik Frustration or Scapegoat}

Teknik propaganda Frustration or Scapegoat digunakan oleh Soedjanmo, Sastro, dan Soedarmo. Teknik propaganda ini menciptakan kebencian atau kambing hitam atas nama suara rakyat yang terpuruk. Permasalahan ekonomi, sosial, dan politik disebabkan oleh pihak yang punya kepentingan. Ketiga tokoh propagandis; Soedjanmo, Sastro, dan Soedarmo menyuarakan sebab yang sama, yaitu penyebab kesengsaraan dan kemiskinan dalam penduduk desa akibat datangnya kapitalisme.

"Ja....tetapi......serenta di dekatnja saja poenja desa ada didiriken seboeah paberik goela jang baroe ada dalem tempo setahoen jang belakangan ini, sekarang saja terpaksa pergi dari saja poenja desa dengen meninggalken saja poenja anak isteri, lantaran..........saja poenja sawah disewa oleh paberik goela itoe, boeat ditanami teboe." (Soemantri, 1924: 40).

"Saja poenja sawah jang sekian banjaknja itoe, disewa oleh paberik seharga f 100 ,- dalem waktoe seoemoer teboe, sedang teboe itoe moelai ditanam sampai digiling adalah 18 boelan lamanja. Doeloe ketika masih saja tanami padi, dalem waktoe jang sekian lamanja itoe bisa menghasilken beberapa pikoel datjin padi jang harganja tentoe berlipat ganda dari pada sewa sawah jang di berikan padakoe oleh paberik itoe. Oeang seratoes roepiah, sekarang.....sebeloem sampai 18 boelan lamanja soedah habis saja makan djoega. Djadi....djadi....sekarang aja terpaksa pergi ke kota besar boeat mentjari penghidoepan. Barangkali di sana bisa memakai saja sebagai koelie" (Soemantri, 1924: 40-41).

Kaum pemodal mengeruk lahanlahan penduduk desa dan menjadikan buruh yang murah sekaligus menciptakan hiburan rakyat dengan 
harapan agar kaum buruh hidup boros.

Sebagaimana dikatakan ketiga propagandis tersebut, pembagian hasil yang tidak merata menyebabkan pertentangan dan peperangan di setiap negara.

\section{Teknik Bandwagon}

Teknik propaganda bandwagon memberikan imbauan kepada masa untuk bergabung dengan gagasan sang propagandis menjadikan kelompok besar. Teknik ini dipergunakan untuk kelompok besar atau masa yang cukup banyak untuk menguatkan idenya, beranggapan kalau dia berada pada kelompok yang benar.

Teknik bandwagon hanya ditemukan dalam propaganda Soedarmo karena propagandanya dilakukan pada masa yang lebih besar. Soedarmo mengajak kepada masa kaum buruh harus meluaskan pikirannya, menaikkan derajatnya, kaum buruh harus bersatu antar bangsa-bangsa agar tidak mudah dipermainkan oleh pihak kapitalis untuk melakukan peperangan, diadu sama manusia lain dengan sekelasnya.

"Kasta boeroeh ini hanja bisa menaik deradjatnja bila dia soedah dan soeka bersatoe dengen segenep bangsabangsa dalem doenia jang bersamaan nasibnja. Kita haroes melinjapken pikiranpikiran koeno, jang meninggi-ninggiken

"vederland" dan kebangsaan, hingga bisa djadi "gila bangsa" jang achirnja moedah dipermainken oleh pertoean, digiring ke medan peperangan diadoe sama lain manoesia jang sekelas dengen dia, padahal dia tidak mengerti apa maksoednja itoe" (Soemantri, 1924: 81).

Soedarmo menambahkan, untuk menghendaki keselamatan dunia, bangsa-bangsa di dunia harus dipersatukan menjadi satu bangsa yaitu "bangsa dunia" tanpa adanya kelas kapitalis dan kelas buruh. Sistem pembagian hasil berdasarkan sistem sama rata, ini diperuntukkan agar hidup aman, tentram, dan tidak ada saling pertengkaran.

"Kita menghendaki keselametan doenia. Dan oentoek mentjapai ini kita haroes bersepakat dengen segala bangsa-bangsa jang sekelas itoe. Kita haroes bikin soepaja dari pada berpoeloeh-poeloeh bangsa didoenja ini djadi "satoe bangsa" sadja, jaitoe "bangsa doenia". Djoega kita poenja tanah toempah darah haroes kita lebarken, selebarlebarnja sebagai batesnja doenia ini. Doenialah tanah toempah darah kita! dan seloeroeh kaoem boeroeh dari berbagai-bagai bangsa haroes bersama-sama menoentoet perbaikan nasipnja, bagi hidoep aman, hidoep tenterem, waktoe mana tidak ada bentji 
membentji jang tidak djarang diteboes dengen toempahnja darah ke moeka boemi" (Soemantri, 1924: 81).

Idealisme Soedarmo diupayakan untuk menghilangkan pertentangan kelas dan perceraian antar manusia. Penjelasan secara emosional ini sengaja diberikan Soedarmo agar menarik masa yang datang, menciptakan keberhasilan propaganda secara maksimal.

\section{Teknik Fear Arousing}

Fear arousing merupakan teknik propaganda untuk membangkitkan ketakutan masa. Propaganda layaknya membuat teror yang pada akhirnya dapat mengancam masing-masing orang. Kondisi ini menjadikan pribadi untuk mengikuti apa kehendak sang propagandis, meyakini apa yang diucapkan.

Teknik propaganda model fear arousing digunakan Soedarmo dalam penguatan idenya. Soedarmo menuturkan, kapitalisme akan megancam keberadaan manusia menuju ke liang kemiskinan.

"Kemadjoean kapitalisme sendiri dalem tiaptiap tanah soedah mendorong pada segolongan dari bangsa di tempat itoe ke liang kemiskinan" (Soemantri, 1924: 77).
Masa menilai, datangnya kapitalisme adalah ancaman yang mengusik kesejahteraan masyarakat. Kata-kata propaganda Soedarmo itu menjadi senjata yang ampuh dalam menarik masa. Membawa masa diperkenalkan menuju landasan ideologi, dan tawaran alternatif untuk menentang kapitalisme.

Dari rangkaian teknik propaganda yang disebutkan di atas, semakin nyata kalau novel Rasa Merdika adalah novel atas kegelisahan penulis. Soemantri memanfaatkan media novel untuk memaparkan kejadian-kejadian kepada rakyat Hindia Belanda. Dibangunnya peristiwa yang diperankan para tokoh-tokohnya sekedar menghidupkan situasi teks agar mudah dipahami oleh pembaca saat itu. Ada kemungkinan besar kalau novel ini dibuat Soemantri atas dasar memperkenalkan ideologi internasionalisme kepada masyarakat luas.

Ideologi internasionalisme pada tahun 1920-an menjadi desas-desus (pembicaraan) di Hindia Belanda bagi kaum pergerakan seusai dibentuknya komintern di Uni Soviet pada tahun 1919. Dalam teks deklarasi Zinoviev menegaskan bahwa komunis internasional telah membuat keputusan untuk mengembangkan 
prinsip-prinsip pergerakan buruh, prinsip-prinsip pergerakan komunis, di seluruh bangsa yang terjajah di seluruh daerah jajahan. Ini adalah tugas pertama komunis internasional. Akan tetapi, pada saat yang sama, komunis internasional juga memutuskan untuk mendukung pergerakan revolusioner rakyat yang terjajah di daerah-daerah jajahan dalam melawan imperialisme, karena komunisme internasional meyakini bahwa kemenangan revolusi proletariat akan membebaskan bangsa yang terjajah. Slogan kami adalah: kaum proletar di seluruh dunia, anda harus bersatu untuk melawan imperialisme, demi komunisme.

Semakin radikal, dan diimbanginya kekuatan masa yang cukup besar, kaum pergerakan Hindia Belanda terkena dampak dari deklarasi Zinoviev. Belianya ideologi kamunisme Hindia Belanda, semakin memudah dan semangat kaum pergerakan mencerna pernyataan dari Lenin. Komunisme negara-negara menjadi kekuatan untuk menentang imperialisme dan kolonialisme, membentuk komunisme internasional. Sehingga antara tahun 1920-1926 kaum nasionalis-komunis menjadi puncak-puncak propaganda kepada semua kalangan.
Kalau kita coba mencermati novel Rasa Merdika, beberapa teknik propaganda yang dilakukan Soedjanmo, Sastro, dan Soedarmo secara sengaja menyuarakan pengetahuan Marxisme kepada pembaca rakyat Hindia Belanda. Gambaran kemiskinan dan kesengsaraan menjadi dasar utama sebagai perekat realitas masyarakat di suatu penduduk desa. Seorang propagandis memberikan fakta spesifik dan argumentasi yang mendukung sebab-sebab kemiskinan di penduduk desa sampai pentingnya membangun komunikasi. Strategi itu sebatas jembatan dasar atau pendukung posisi untuk melancarkan propaganda agar si target (komunikan) bisa menerima secara logis dan meyakininya.

\section{SIMPULAN}

Propaganda yang berhaluan internasionalisme dalam novel Rasa Merdika mempu merepresentasikan kondisi zamannya. Perjuangan kelas sosial dan kritik tradisi menjadi dasar utama ide novel ini diciptakan. Kehadiran teks propaganda tidak muncul secara tiba-tiba, ada beberapa penyebab atau persoalan sehingga suatu propaganda menjadi alasan untuk alat membangun basis atau mempengaruhi masa (pembaca). Beberapa 
kebijakan pemerintah dan pihak pemodal yang sangat menyengsarakan rakyat secara mendasar menjadikan alasan kaum pergerakan buruh untuk melakukan propaganda. Selain itu, faktor ekonomi juga menjadi penyebab kaum pergerakan melakukan tindakan yang radikal. Bentuk propaganda ini bersifat mempengaruhi kaum kromo, untuk memberikan pengetahuan modern sekaligus bersedia bertindak untuk melawan pemerintah, menuntut hak-hak buruh, menuntut sistem rasial, dan menekan mundur pihak kolonial.

Novel Rasa Merdika adalah media naratif yang bermuatan propaganda ideologi internasionalisme maupun nasionalisme Hindia. Propaganda utama ditujukan kepada rakyat kromo, Soemantri beranggapan kalau kalangan masyarakat

ini lebih efektif sebagai pemicu perlawanan karena sikap emosionalnya sudah terbentuk akibat peristiwa yang dialaminya. Hal inilah yang menjadi dasar Soemantri untuk memakai gaya penulisan bahasa Melayu pasar, yang bertolak dari konsep penerbit Balai Pustaka. Tujuan Soemantri adalah supaya rakyat kromo yang berpendidikan rendah ini mampu memahami sepenuhnya terhadap teks yang disampaikan. Dengan demikian, berbagai teknik propaganda tersebut sebagai langkah Soemantri supaya narasi-narasi teks yang disajikan dapat dinikmati dan diaplikasikan oleh pembaca agar masyarakat memiliki kesadaran tentang tanah air Hindia. Namun, pemerintah merespon bacaan tersebut dinilai berbahaya, bahkan dapat mengancam status pemerintah kolonial di Hindia. Kemudian pemerintah mengambil langkah untuk mengancam beredarnya bacaan tersebut dengan pasal-pasal 154, 1555, 156, 157, dan 161 di Strafwetboek.

\section{DAFTAR PUSTAKA}

Azwar, Saifuddin. 2005. Metode Penelitian. Yogyakarta: Pustaka Pelajar.

Combs, James Edem dan Dan Dimmo. 1994. Propaganda Baru: Keditaktoran Perundingan dalam Politik Masa Kini (Lien Amelia, penerjemah). Bandung : PT Remaja Rosdakarya.

Diah Haryanti, Novi. 2009. Pendekatan Pascakolonial dalam Student Hidjo dan Rasa Merdika Karya Mas Marco Kartodikromo. Jurnal Semiotika. Edisi 10 (1) JanuariJuni.

Dwigiht Lasswell, Harold. 1972. Propaganda Technique in The Word War. New York : Garland Publishing. 
McVey, Ruth T. 1965. The Rise Of Indonesia Communism. New York : Cornell University Press.

Razif. 2005. Bacaan Liar Budaya dan Politik pada Zaman Pergerakan. Jakarta : Edi Cahyono Experience.

Sastropoetro, RA Santoso. 1991.

Propaganda: Salah Satu Bentuk Komunikasi Masa. Bandung : Alumni.

Shoelhi, Mohammad. 2012. Propaganda Dalam Komunikasi Internasional. Bandung : Simbiosa Retakama Media.

Selden, Raman. 1985. A Reader's Guide To Contemporary Literary Theory. Kentucky : Kentucky University Press.

Soemantri. 1924. Rasa Mardika (Hikayat Soedjanmo). Semarang : Drukkerij VSTP.

Soegiri DS dan Edi Cahyono. 2003. Gerakan Serikat Buruh Jaman Kolonial Hindia Belanda Hingga Orde Baru. Jakarta : Hasta Mitra.

Sumarjo, Yakob. 2004. Kesusastraan Melayu Rendah Masa Awal. Yogyakarta : Galang Press.

Sulton, Agus. 2015. Sastra Bacaan Liar Harapan Menuju Kemerdekaan.
Jurnal Bahasa \& Sastra. Vol 15 (2) Oktober.

Sulton, Agus. 2020. Mas Marco Kartodikromo's Resistance in 1914-1926: Between Indonesia's Independence Hope and Persdelict Threat. International Journal of Scientific \& Technology Research. Volume 9 (01). January 2020.

Toer, Pramoedya Ananta. 2003. Realisme Sosialis dan Sastra Indonesia. Jakarta : Lentera Dipantara.

Wasono, Sunu. 2007. Sastra Propaganda. Jakarta : Wedatama Widya Sastra.

W. Doop, Leonard. 1950. Public Opinion and Propaganda. New York: Henry Holt and Company.

Yuliati, Dewi. 2012. Nasionalisme Buruh Dalam Sejarah Indonesia. Jurnal HUMANIKA FIB Universitas Diponegoro Semarang. Vol 16 (9). 